\title{
OBITUARY
}

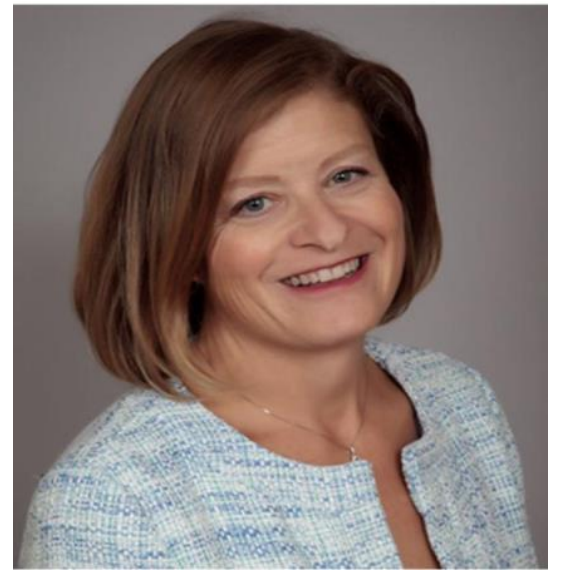

\section{Lisa J. Stearns, MD}

Lisa Stearns, MD, Founder \& Medical Director at Center for Pain and Supportive Care, Phoenix, USA, breathed her last on 31 May 2020 at her home in Mexico.

As a physician, she was a valiant warrior. Her pursuit of novel methods, innovation, and creative approaches contributed widely to the practice of pain medicine globally. Courageous, stubbornly committed, and always compassionate, she was one of the heroes in the epidemic of pain and suffering. She was the founding Board Member of Cancer Pain Research Consortium (CPRC). At last year's Annual Conference, Lisa delivered a lecture on death and dying in her cancer pain practice. She talked about death and the afterlife. She discussed how her patients of various cultures celebrated their life, anticipated death, pondered the afterlife, and grieved with their families.

Lisa Stearns founded Valley Cancer Pain Foundation and remained its president till now. It is a non-profit organization dedicated solely to cancer pain research, to raise awareness, educate families, patients and providers on integrating interventional pain treatments.

One of her great achievement has been the Center for Pain and Supportive Care, of which she remained Medical Director till end. The center provides innovative, personalized, and holistic pain management treatments to improve overall function and quality of life for patients.

She remained committed to academic development of pain management and served as Outside Consultant, Adjunct Faculty in Department of Palliative Care, Mayo Clinic Arizona, Scottsdale, AZ, and Medical Director of Scottsdale Healthcare Systems Palliative Care Program till her demise.

Lisa has been an internationally renowned interventional pain specialist, board-certified in hospice and palliative medicine and pain management.

All members of Editorial Board of 'Anaesthesia, Pain \& Intensive Care' express great sorrow on her demise. RIP!

Tariq H. Khan, MCPS, FCPS

Editor-in-Chief 
